\title{
Introduction: Beyond Orientalism; Texting the Victorian East
}

\author{
JULIA KUEHN AND TAMARA S. WAGNER \\ (Guest Editors)
}

Thirty years after its publication in 1978, a reconsideration of Edward Said's Orientalism invites a shift from contextual and colonial discourse analysis towards a renewed attention to ambiguities of form and structure. The central point of interest of this special issue, 'ReImagining the Victorian Orient', hinges upon close readings of canonical and noncanonical texts, side by side, in order to highlight the complexities of Victorian literary culture that earlier readings often threatened to deny. The analyses comprise discussions of travel writing as well as of fiction from the 1830s up to the 1920s, covering what is commonly considered the height of imperialism. What brings the essays in this special issue together is the project of opening up the question of the Victorian Orient as a concept and a literary topos, based upon, but also beyond the critical tenets of Orientalism. While this project is rooted in literary history and the history of representation, its main emphasis firmly rests on a 'texting' of the Victorian East: an emphasis on genre, aesthetics, and structural metaphors. This collection is held together by the places it foregrounds as much as by this critical redirection towards textual analysis. Divided into two parts, it reads women's travelogues covering the Middle East, South, and South East Asia, comparing and contrasting them with the 'notorious' colonial novels of Dickens, Conrad, Kipling, and Forster.

This special issue thus participates in the larger debate about where to go next in Victorian studies. While acknowledging the importance of a continuously expanding canon, the historical situatedness of authors, texts, and readers, and the necessity of looking beyond national boundaries, it first and foremost demands a return to the texts. Precisely because of the now so common, perhaps simplistic, 
association of colonial texts with colonialist discourse analysis, their reassessment through narrative parameters provides a particularly salient starting point for such an interrogation. What is really the Victorians' interest in the Orient, and what forms of representation does it take?

Muireann O'Cinneide's essay moves right to the heart of the matter to investigate how the epistemological 'interest' in difference is articulated and performed in the travel writings of Emily Eden, Francis Harriet Egerton, and Anne Blunt. For markedly different reasons and driven by different agendas, these three women travelled across diverse regions of the East, all targeting in their writing the uninformed domestic reader. Likewise drawing on Emily Eden's $U p$ the Country, Pablo Mukherjee enquires further into the worldliness of the text. Reading this travelogue alongside a number of historical documents on colonial governance, economics, and politics, his essay merges aesthetic concerns about Eden's creation of a 'colonial picturesque' with, paradoxically, historical representations of famine. Robert Hampson's essay forms a transition piece in that it reads actual female travellers in colonial Malaya not through the standard critical classification by manner of travel ('accompanying women', 'unprotected females', tourists), but through a functional taxonomy derived from Conrad's fiction. His female travellers, including Isabella Bird, Anna Forbes, Marianne North, Sara Jeannette Duncan, and Annie Brassey, are shown to negotiate and transgress the boundaries established by conventional travel writing criticism.

Alison Sainsbury's essay forms a point of entry into the second half of this collection. In its focus on E.M. Forster's A Passage to India, it constitutes a break with chronology within this collection, but it vitally connects the actual experience of the East with its fictional representations. It also provides a bridge between differently gendered texts by reading Forster's novel through the conventions of AngloIndian domestic fiction and by focusing on the changing functions of the trope of motherhood. Grace Moore's essay then discusses the accumulation and consumption of imperial artefacts in Dickens's later fiction, pointing to the novelist's concern regarding the dangers of empire, as the centre's appetite for imported and consumed colonial commodities in the end invariably produces imperial waste. Albeit in a less economic and market-oriented sense, the following essay by Kaori Nagai expands on the idea of the Victorian interest in the Orient as being one of movement and flux, and constantly undergoing 
negotiation. In a comparative reading of Kipling's short fiction and Conrad's Lord Jim, Nagai shows this negotiation between the works of, and discourses created by, two individual authors. Her focus is on one particular trope, 'the Man who would be King', and its different functions as structural metaphor and colonial fantasy. Katherine Baxter's essay concludes this special issue by interrogating in more detail the conflict between the historical and literary colonial romance, and colonial realities. In a close reading of Lord Jim, she shows how important the explosion of colonial fantasy is to the East's representation in Victorian fiction. This evinces once more the complexity and fragility of the Victorians' texting of 'the Orient' and our engagement with Orientalism/Orientalism. 